NBER WORKING PAPER SERIES

PRICE UNCERTAINTY AND PRICE-CONTINGENT SECURITIES

\author{
Geoffrey Heal \\ Working Paper 23723 \\ http://www.nber.org/papers/w23723 \\ NATIONAL BUREAU OF ECONOMIC RESEARCH \\ 1050 Massachusetts Avenue \\ Cambridge, MA 02138 \\ August 2017
}

Research support from Columbia Business School is acknowledged. The views expressed herein are those of the author and do not necessarily reflect the views of the National Bureau of Economic Research.

NBER working papers are circulated for discussion and comment purposes. They have not been peer-reviewed or been subject to the review by the NBER Board of Directors that accompanies official NBER publications.

(C) 2017 by Geoffrey Heal. All rights reserved. Short sections of text, not to exceed two paragraphs, may be quoted without explicit permission provided that full credit, including () notice, is given to the source. 
Price Uncertainty and Price-Contingent Securities

Geoffrey Heal

NBER Working Paper No. 23723

August 2017

JEL No. D5,D53,G13

\begin{abstract}
$\underline{\text { ABSTRACT }}$
I extend the classical general equilibrium treatment of uncertainty about exogenous states of nature to uncertainty about prices. Traders do not know the prices at which markets will clear but have expectations over possible prices. They trade price-contingent securities (derivatives) to insure against the risks arising from this uncertainty. I establish four results. One is set of conditions that are necessary and sufficient for the existence of equilibrium (called an equilibrium with price insurance) in this framework. A second is that equilibria with price insurance are Pareto efficient. I give conditions under which agents are fully insured at an equilibrium. Finally I show that agents' price expectations matter in the sense that they affect the equilibrium allocation of resources, and that the existence of price-contingent securities alters the equilibrium of the underlying real economy.
\end{abstract}

Geoffrey Heal

Graduate School of Business

516 Uris Hall

Columbia University

New York, NY 10027-6902

and NBER

gmh1@columbia.edu 


\title{
PRICE UNCERTAINTY AND PRICE-CONTINGENT SECURITIES
}

\author{
GEOFFREY HEAL
}

\begin{abstract}
I extend the classical general equilibrium treatment of uncertainty about exogenous states of nature to uncertainty about prices. Traders do not know the prices at which markets will clear but have expectations over possible prices. They trade price-contingent securities (derivatives) to insure against the risks arising from this uncertainty. I establish four results. One is set of conditions that are necessary and sufficient for the existence of equilibrium (called an equilibrium with price insurance) in this framework. A second is that equilibria with price insurance are Pareto efficient. I give conditions under which agents are fully insured at an equilibrium. Finally I show that agents' price expectations matter in the sense that they affect the equilibrium allocation of resources, and that the existence of price-contingent securities alters the equilibrium of the underlying real economy.
\end{abstract}

\section{Price Uncertainty}

Uncertainty about prices has a real welfare cost, just as does uncertainty about exogenous events such as earthquakes or tropical storms. Prices may affect the value of our endowments, and there is naturally interest in insurance against this risk. In advanced economies uncertainty about prices is probably more extensive and more costly than uncertainty about states of nature (as argued by Shiller [1993]).

There are many markets that meet some of this demand for insurance against price risks. Options and futures and swap markets, indeed derivative markets in general, are used extensively to insure against price risks, yet until recently there have been few attempts to incorporate price uncertainty into the classical ArrowDebreu general equilibrium framework. There is an extensive discussion of the use of derivative to hedge price risks in the finance literature, but the models used there are not intended to shed light on issues such as the impact of derivative markets on the overall allocation of risk in the economy, or on interactions between derivative markets and the underlying markets for goods and services. These questions are the focus of this paper: the aim is to establish a framework within which we can think systemically about interactions between markets for price risks and markets for goods and services.

How derivatives affect the overall allocation of risks within the economy is particularly pertinent in view of the interest of regulators in the possible systemic risks associated with derivative markets. Adding to this is the fact that for many securities the volume of trade in derivatives now exceeds that in the underlying asset. This suggests that trade in derivative markets might influence the equilibria

Date: August 2017.

Key words and phrases. derivatives, price uncertainty, endogenous uncertainty, general equilibrium, price expectations, Hilbert space. 
in the underlying asset markets, calling into question the premises of some option valuation models and suggesting a possible systemic impact.

This paper suggests that the introduction of derivative markets in an ArrowDebreu general equilibrium model with price uncertainty leads to an improvement in resource allocation, with agents benefitting from the ability to insure otherwise uninsurable risks. There is no evidence of the multiplication of risks or of systemic risks that have worried regulators.

Earlier work (Chichilnisky et al. [1994], Dreze [1999], Hahn [1999]) has suggested that uncertainty about prices, which are determined endogenously within the economic system, is conceptually more complex than uncertainty about exogenous states of nature, with the implication that it is difficult if not impossible to use price-contingent contracts to manage these risks. In fact there is a very natural and conceptually simple extension of the classical general equilibrium framework to price uncertainty, involving the use of price-contingent securities. This provides a simple and satisfactory account of the welfare and general equilibrium roles of derivatives in hedging price uncertainty in a complete general equilibrium framework.

1.1. The Framework. I work with a classical exchange economy augmented by the possibility of trading price-contingent securities (PCSs) which pay a specified sum if and only if the equilibrium price vector assumes a specified value. ${ }^{1}$ Prices play the role of "states of nature" in the Savage or Arrow-Debreu frameworks, but here the state is determined endogenously, in contrast to the states in the more traditional frameworks.

Agents hold expectations about possible prices. Before an equilibrium prices is realized, they trade price contingent securities, shifting income from price states where they are well off to those where they are badly off. This changes their endowments in the underlying exchange economy: in addition to conventional endowments of goods and services they hold price-contingent securities that alter the market values of their total endowments in a way that depends on the price vector realized.

I do not discuss the source of agents' price expectations. It suffices to assume that they do not know the prices that will rule in a forthcoming market equilibrium and in lieu of this knowledge form expectations. There are many possible explanations for this. To forecast prices accurately an agent would have to know the preferences and endowments of all other agents, and then be able to compute the equilibrium of the system. Realistically an agent could fail at any stage of this process - could not know the preferences or endowments of some others, or could know these but not have the necessary computational skills. Alternatively, there may be multiple equilibria so that even knowledge of the model and the ability to compute its outcomes leaves uncertainty about prices. Chichilnisky et al. [1994] consider the case of an economy with multiple equilibria, all of which are known to the participants in the economy, although they do not know which will be realized: there agent's expectations are restricted to the set of equilibrium prices. Hahn

\footnotetext{
${ }^{1}$ Such securities have been discussed in the context of a temporary equilibrium model by Svensson [1981], and earlier in a growth model by Stigum [1972]. These authors and others (Kurz and Wu [1996], Henrotte [1992]) have also discussed such securities in a Walrasian framework, but none have embedded them in the standard general equilibrium framework. de Temple and Selden [1991] look at the interactions between options markets and markets for the underlying securities.
} 
also focuses on this case, making the point that rational expectations are logically impossible in this context. For all these reasons it seems eminently plausible that agents do not know the prices that will rule in a market that is about to open, but will have expectations about these and will seek to hedge risks generated by this lack of knowledge.

We can think of agents as making their choices in two stages. In the first stage they choose portfolios of PCSs in the light of the values of their endowments at different prices and their expectations about equilibrium prices. Each chooses a PCS portfolio which maximizes expected utility over equilibrium prices, given their expectations over prices and given their endowments. Once agents have chosen portfolios of PCSs, equilibrium prices are realized. ${ }^{2}$ Now given the equilibrium prices, agents choose consumption vectors to maximize utility subject to their budget constraints (which depend on their holdings of PCSs). At this stage they face no uncertainty and act exactly as in a standard exchange economy, except for the dependence of their endowments on prices.

In modeling this framework we derive an indirect utility function relating an agent's expected utility from consumption to her holdings of PCSs: agents select portfolios to maximize this function. Together with securities prices, this generates demands for and supplies of securities: the net endowment of any security is zero.

An equilibrium of the entire system, called an equilibrium with price insurance, is an equilibrium in both the goods and the PCS markets. I establish the following results: (1) conditions on preferences and price expectations necessary and sufficient for the existence of such an equilibrium (these conditions require that price expectations overlap in a sense to be made clear), (2) the Pareto efficiency of these equilibria, which provide agents with insurance against the uncertainty represented by their prices expectations (3) conditions under which agents are fully insured by the PCS markets and (4) that agents' price expectations influence the equilibrium allocation of resources, that is, derivative markets affect the outcomes in markets for goods and services. This is of course in the context of a complete set of markets, and so is different from the phenomena that occur in models with incomplete markets or with temporary equilibria.

If goods and contracts contingent on their prices are traded in the same markets, then arbitrage will prevent the securities markets from playing a positive role. Once the prices of goods are announced, then it is immediately clear that only certain price-contingent securities can have non-zero prices. To avoid this difficulty, we have to separate the two sets of markets and prevent arbitrage. In real markets, options and other PCSs are traded before the trading of the goods on whose prices they are contingent: this is a natural arbitrage-free structure, which I use here.

In the next section I provide simple geometric illustrations of the main concepts and results of the paper. Then I set out the general model, assumptions, definitions and results: proofs are in the appendix.

\section{Illustrations}

In this section I give two examples of how the introduction of PCSs can affect the equilibrium allocation of goods and services in a competitive economy. They

\footnotetext{
${ }^{2}$ These depend on the portfolios that people have chosen, but, consistent with the standard competitive assumption, they do not take this into account.
} 
also give some intuition about how the general case works. The examples use a two-person two-good economy which can be illustrated by an Edgeworth box.

There are two risk-averse agents and with right-angled indifference curves. This means that there are infinitely many competitive equilibria when this economy is considered as an exchange economy of the Arrow-Debreu type. The introduction of price uncertainty and PCSs (which are traded before prices are determined and which allow this to be insured) leads to a unique equilibrium allocation and the removal of all price risks.

Agents' preferences are given by $u_{i}=\log \left(\min \left\{c_{i 1}, c_{i 2}\right\}\right), i=1,2$, where $c_{i j}$ is agent $i$ 's consumption of good $j, j=1,2, c_{i}=\left(c_{i 1}, c_{i 2}\right)$. These combine right-angled preferences - which make the determination of equilibria easy - with risk aversion. The total endowment of each of the two goods is one unit, and agent's endowments are $\Omega_{1}=(1,0)$ and $\Omega_{2}=(0,1)$, placing the endowments at the lower right corner of the Edgeworth box. We let $p=\left(p_{1}, p_{2}\right)$ be a price vector $\left(p_{1}+p_{2}=1, p_{j} \geq 0 \forall j\right)$. Note that any strictly positive price vector can be an equilibrium price vector.

Agent $i$ 's holdings of price-contingent securities are represented by $s_{i}(p) \gtrless 0$, which gives the amount she will receive or pay as a function of the equilibrium price vector in the exchange economy. At a goods price vector $p$ agents' choice problems are

$$
\max _{c_{i}} u_{i}=\log \left(\min \left\{c_{i 1}, c_{i 2}\right\}\right), p_{1} c_{i 1}+p_{2} c_{i 2}=p_{i}+s_{i}(p)
$$

Demands are given by

$$
c_{11}=c_{12}=\frac{p_{1}+s_{1}(p)}{p_{1}+p_{2}}=p_{1}+s_{1}(p) ; c_{21}=c_{22}=\frac{p_{2}+s_{2}(p)}{p_{1}+p_{2}}=p_{2}+s_{2}(p)
$$

Given that $s_{1}(p)+s_{2}(p)=0 \forall p$ and $p_{1}+p_{2}=1$, it is clear that these demand functions clear the markets at any prices. As agents consume equal amounts of both goods, we can write their utilities as function of just the amount of the first good they consume, which is $p_{i}+s_{i}(p)$. If there are no PCSs then any point on the diagonal of the Edgeworth box (i.e. any point on the contract curve) is a competitive equilibrium at some suitable price vector.

In the case when there is a market for PCSs, agents choose securities holdings to maximize expected utility, given their price expectations. First we consider a case in which agents' expectation over prices are particularly simple: both expect that prices will be either $\tilde{p}=(0.25,0.75)$ or $\hat{p}=(0.75,0.25)$, and that these two outcomes are equally likely. Agent 1 therefore seeks to solve the problem

$$
\max _{s_{1}}\left\{0.5 \log \left(0.25+s_{1}(\tilde{p})\right)+0.5 \log \left(0.75+s_{1}(\hat{p})\right)\right\}
$$

subject to the securities budget constraint

$$
\pi(\tilde{p}) s_{1}(\tilde{p})+\pi(\hat{p}) s_{1}(\hat{p})=0
$$

Here $\pi(p)$ is the price of a PCS that pays one unit if and only if the market price vector is $p$. Let $\lambda_{1}$ be the Lagrange multiplier associated with agent 1's optimization problem: then from the first order conditions for optimality we have that

$$
s_{1}(\tilde{p})=\frac{1}{2 \lambda_{1} \pi(\tilde{p})}-0.25: s_{1}(\hat{p})=\frac{1}{2 \lambda_{1} \pi(\hat{p})}-0.75
$$


with analogous results for agent 2:

$$
s_{2}(\tilde{p})=\frac{1}{2 \lambda_{2} \pi(\tilde{p})}-0.75: s_{2}(\hat{p})=\frac{1}{2 \lambda_{2} \pi(\hat{p})}-0.25
$$

Recalling that $s_{1}(\tilde{p})+s_{2}(\tilde{p})=0=s_{1}(\hat{p})+s_{2}(\hat{p})$ we now have that $\pi(\tilde{p})=$ $\frac{1}{2 \lambda_{1}}+\frac{1}{2 \lambda_{2}}=\pi(\hat{p})$. Hence securities prices are independent of which of the two expected underlying goods price vectors is realized, and agents' consumption levels, given by $p_{i}+s_{i}(p)$, are also independent of which of these equilibrium prices is realized. ${ }^{3}$

Note that the existence of markets for PCSs has not changed the equilibrium prices in the goods market: rather it has altered the equilibrium allocation of consumption between agents, allowing them to smooth consumption across price states. If the agents' expectations did not agree, in the sense that agent one expected prices $\hat{p}$ and $\tilde{p}$ while agent two expected prices $\check{p}$ and $\breve{p}$, these being four distinct price vectors with no two equal, then there would be no trade in PCSs and so no impact from the existence of such securities.

Now we consider a more complex case. Agents' price expectations are uniform over all possible prices. Agent 1 seeks to solve the following problem:

$$
\max _{s_{1}(p)} \int_{0}^{1} \log \left\{p_{1}+s_{1}(p)\right\} d p_{1}: \int_{0}^{1} s_{1}(p) \pi(p) d p=0:
$$

The second integral here is the budget constraint in the securities market. This makes the problem an isoperimetric problem in calculus of variations. Writing down a Hamiltonian for this problem and taking first order conditions yields for each agent the following equations:

$$
s_{1}(p)=\frac{1}{\lambda_{1}(p) \pi(p)}-p_{1}: s_{2}(p)=\frac{1}{\lambda_{1}(p) \pi(p)}-p_{2}: \frac{\partial \lambda_{i}(p)}{\partial p}=0 \forall i
$$

so the shadow prices $\lambda_{i}$ are constants independent of $p$, and it can then be shown that $\pi$ is a constant independent of $p$. Hence $s_{1}+p_{1}$ and $s_{2}+p_{2}$ are constants which means that each agent's consumption is independent of the goods prices in the exchange economy.

In this case, as in the first, the existence of PCS markets has not altered the equilibrium prices in the goods markets: these are whatever they would otherwise have been. It has however altered the allocation of goods between people in such a way as to remove price risk. PCSs do this by altering endowments in a way that depends on the price vector realized.

\section{The General Model}

The economy $\mathcal{E}$ that we consider can be defined formally as follows:

(1) There are $n$ markets for goods and services, and in addition a complete set of markets for price-contingent securities, i.e. markets for contracts which will pay one unit of account on the realization of any price vector in the simplex $\Delta \subset \mathfrak{R}_{+}^{\mathfrak{n}} \cdot{ }^{4}$

\footnotetext{
${ }^{3}$ If neither $\hat{p}$ nor $\tilde{p}$ is realized then agents' budget constraints are unchanged from those in the underlying exchange economy and the outcome is whatever it would have been without PCSs .

${ }^{4} \Delta=\left\{p \in \Re_{+}^{n}: \sum_{j} p_{j}=1, p_{j} \geq 0 \forall j\right\}$
} 
(2) A portfolio of securities is an element of the space of functions from the price simplex to the real line: it assigns to each price vector a number which is the value of securities held contingent on that price vector. A security pays one unit if and only if a specified price vector is realized as the equilibrium price vector, and a portfolio specifies the quantity of securities held contingent on each possible price vector. We take the space of portfolios to be Hilbert space $L_{2}$, the space of measurable square integrable functions from $\Delta \subset \mathfrak{R}_{+}^{\mathfrak{n}}$ to the real line. This has the norm $\|s\|=\left[\int_{\Delta} s(p)^{2}\right]^{1 / 2}$ and inner product $\langle x, y\rangle=\left[\int_{\Delta} x(p) y(p) d p\right]$. Securities are elements of the dual to this space and as $L_{2}$ is self-dual, both securities and portfolios are in $L_{2}$.

(3) There are I agents, $i \in I$. Agents are characterized by endowments $\Omega_{i} \in$ $\mathfrak{R}_{+}^{\mathfrak{n}}$, preferences $u_{i}: \mathfrak{R}_{+}^{\mathfrak{n}} \rightarrow \mathfrak{R}$, and price expectations $e_{i}: 2^{\Delta} \subset \mathfrak{R}_{+}^{\mathfrak{n}} \rightarrow \mathfrak{R}$, where $2^{\Delta}$ is the $\sigma$-algebra of subsets of $\Delta$ and $e_{i}(p)$ is a probability measure representing agent $i$ 's expectations over possible prices in the simplex. $e_{i}(p)$ is measurable with respect to the $\sigma$-algebra. Agents choose portfolios of PCSs in the securities markets and the payoffs from these are a part of their endowments in the goods markets.

(4) Consumption sets are the non-negative orthant $\mathfrak{R}_{+}^{\mathfrak{n}}$ for goods and $L_{2}$ for securities, so unbounded short sales are allowed for PCSs but not for goods. This seems a natural combination, although other possible combinations could equally well be covered.

(5) Prices in the goods markets are vectors in $\mathrm{p} \in \boldsymbol{\Delta} \subset \mathfrak{R}_{+}^{\mathfrak{n}}$, and those in securities markets are functions $\pi(p): \Delta \rightarrow \mathfrak{R}$ giving the cost of a security that pays one unit if and only if the price is $p$.

3.1. Behavior in the goods market. Consider behavior in the goods market once an equilibrium price vector $p \in \Delta$ is known. Agent $i$ solves the problem

$$
\max _{c_{i}} u_{i}\left(c_{i}\right), \quad p \cdot c_{i} \leq p \cdot \Omega_{i}+s_{i}(p)
$$

Here utility is maximized subject to a standard budget constraint augmented by the proceeds of trading in the securities market. Denote the maximum of utility subject to this constraint by $w_{i}\left(p, s_{i}(p), \Omega_{i}\right)$. As $\Omega_{i}$ will be held fixed in what follows, we suppress dependence on this and write

$$
w_{i}\left(p, s_{i}(p)\right)=\max _{c_{i}} u_{i}\left(c_{i}\right): p . c_{i} \leq p \cdot \Omega_{i}+s_{i}(p)
$$

So $w_{i}\left(p, s_{i}(p)\right)$ denotes the maximum utility attainable if the goods market price vector is $p$, as a function of the payoff in this state of PCSs purchased in the securities market. ${ }^{5}$ This is an indirect utility function. We can also derive a demand function $d_{i}\left(p, s_{i}(p)\right)$ showing $i$ 's demand for goods if the price vector is $p$ and securities holdings are $s_{i}(p)$. Clearly

$$
w_{i}\left(p, s_{i}(p)\right)=\max _{c_{i}} u_{i}\left(c_{i}\right): p . c_{i} \leq p \cdot \Omega_{i}+s_{i}(p)=u_{i}\left(d_{i}\left(p, s_{i}(p)\right)\right)
$$

\footnotetext{
${ }^{5}$ We can write it $w_{i}^{p}\left(s_{i}(p)\right)$ to show that it can also be interpreted as a state-dependent utility function if prices are viewed as states.
} 
3.2. Behavior in the securities market. As the goods market price $p$ is seen as a random variable, agents seek to pick securities so as to maximize the expected utility from goods, given the wealth resulting from securities holdings and endowments. We can write this as

$$
\max _{s_{i}(p)} W_{i}\left(s_{i}(p)\right) \equiv \int_{p \in \Delta} w_{i}\left(p, s_{i}(p)\right) d e_{i}=\int_{p \in \Delta} u_{i}\left(d_{i}\left(p, s_{i}(p)\right)\right)
$$

The maximand is the expected utility in the goods market, given the agent's price expectations and holdings of securities. Maximization is with respect to the function $s_{i}(p): \Delta \rightarrow \mathfrak{R}$ defining $i$ 's portfolio of PCSs. The budget constraint in the securities market is

$$
\int_{\Delta} \pi(p) s_{i}(p) d p=0
$$

This is the inner product of a price vector with a portfolio vector, both in $L_{2}$. In addition to the budget constraint, there is a constraint stating that an agent cannot sell more income in a price state than she will have in that state:

$$
p . \Omega_{i}+s_{i}(p) \geq 0 \forall p
$$

Hence the agent's optimal choice of PCSs solves the problem

$$
\max _{s_{i}(p)} \int_{p \in \Delta} w_{i}\left(p, s_{i}(p)\right) d e_{i}: \int_{\Delta} \pi(p) s_{i}(p) d p=0 \& p \cdot \Omega_{i}+s_{i}(p) \geq 0 \forall p
$$

This, like the second example in section 2 , is an isoperimetric problem: let $s_{i}(p)$ be the solution. The in the goods market the agent seeks to

$$
\max _{c_{i}} u_{i}(c): p . c_{i} \leq p \cdot \Omega_{i}+\stackrel{\circ}{s}_{i}(p)
$$

\section{Assumptions and Definitions}

In this section I set out the assumptions used about consumer preferences and expectations, and the definitions of some technical concepts that will be used in the proofs of existence of equilibrium. The strategy of the proof is first to show that the underlying exchange economy has an equilibrium, and then to show that the overall economy with securities markets also has an equilibrium. Conditions sufficient for the exchange economy to have an equilibrium are well-known: here I give conditions that are necessary as well as sufficient, and then give results that are necessary and sufficient for existence of equilibrium in the entire system, based on results in Chichilnisky and Heal [1998]. This makes the arguments slightly more complex than if we were to focus just on sufficient conditions.

Consumers have preferences over goods, and indirectly have preference over securities. Preferences over goods are assumed to satisfy the following conditions:

Assumption 1. Each agent has preferences represented by a strictly concave continuously differentiable function $u_{i}: N\left(\mathfrak{R}_{+}^{\mathfrak{n}}\right) \rightarrow \mathfrak{R}$ (where $N\left(\mathfrak{R}_{+}^{n}\right)$ is a neighborhood of $\left.\mathfrak{R}_{+}\right)$such that $u_{i}(0)=0$, sup $u_{i}(x)=\infty, \exists \epsilon, \delta>0: \forall x \in N\left(\mathfrak{R}_{+}^{\mathfrak{n}}\right), 0<\epsilon \leq$ $x \in \mathfrak{R}_{n}^{+}$

$\left\|D u_{i}(x)\right\| \leq \delta$ where $D u_{i}(x)$ is the first derivative of the function $u_{i}$ at $x$.

Assumption 2. If an indifference surface through a positive consumption bundle $c$ intersects a boundary ray $r$ of $\mathfrak{R}_{+}^{\mathfrak{n}}$ then every indifference surface containing points preferred to $c$ also intersects the ray $r$.

Assumption 2 is satisfied by many standard preferences on $\mathfrak{R}_{+}^{\mathfrak{n}}$, such as CobbDouglas, CES, linear preferences, most Leontieff preferences and smooth utilities 
defined on a neighborhood of the positive orthant which are transversal to its boundary.

Assumption 3. The indirect utility function $W_{i}\left(p, s_{i}(p)\right)$ is normalized so that the expected indirect utility $W_{i}\left(s_{i}(p)\right)$ satisfies $W_{i}(0)=0$ and $\sup _{s \in L_{2}} W_{i}=\infty$.

Assumption 4. The expected indirect utility $W_{i}\left(s_{i}(p)\right)$ satisfies one of the following two conditions: either each indifference surface is bounded below or the set of supports to each indifference surface is a closed set.

Definition 1. The goods global cone $A_{i}$ of agent $i$ consists of all directions in the space of goods along which i's utility increases without bound:

$$
A_{i}\left(\Omega_{i}\right)=\left\{z \in \mathfrak{R}^{n}: \forall y \in \mathfrak{R}^{n}, \exists \lambda>0: u_{i}\left(\Omega_{i}+\lambda z\right)>u_{i}(y)\right\}
$$

Definition 2. The cone $G_{i}$ of agent $i$ is the set of directions in the space of goods along which $i$ 's utility never ceases to increase:

$$
G_{i}\left(\Omega_{i}\right)=\left\{z \in \mathfrak{R}^{n}: \forall \mu \exists \lambda: u_{i}\left(\Omega_{i}+\lambda z\right)>u_{i}\left(\Omega_{i}+\mu z\right) \text { if } \lambda>\mu \geq 0\right\}
$$

Under assumption 1 the cone $G_{i}\left(\Omega_{i}\right)$ contains the cone $A_{i}\left(\Omega_{i}\right)$ and in addition contains some of the boundary rays of $A_{i}\left(\Omega_{i}\right)$.

Let $D_{i}$ be the dual to the cone $G_{i}$ :

$$
D_{i}=\left\{p \in R_{+}^{n}: \forall z \in G_{i}, p . z>0\right\}
$$

and let $S(\mathcal{F})$ be the set of prices that support efficient individually rational and affordable allocations in the underlying exchange economy $\mathrm{E}$ and $N$ the set of prices which assign some agent zero wealth. Formally

$$
\mathcal{F}=\left\{\begin{array}{c}
c_{i} \in \mathfrak{R}_{+}^{n}: \sum_{i} c_{i} \leq \sum_{i} \Omega_{i} \& \forall i, u_{i}\left(c_{i}\right) \geq u_{i}\left(\Omega_{i}\right) \& \text { not } \exists y_{i} \in \mathfrak{R}_{+}^{n} \text { with } \\
\sum_{i} y_{i} \leq \sum_{i} \Omega_{i} \& \forall i, u_{i}\left(y_{i}\right) \geq u_{i}\left(c_{I}\right) \& \exists j: u_{j}\left(y_{j}\right)>u_{j}\left(c_{j}\right)
\end{array}\right\}
$$

Then

$$
\begin{gathered}
S(\mathcal{F})=\left\{p \in \Delta: \text { p supports allocations in } F \& p . c_{i}=p \cdot \Omega_{i}+s_{i}(p)\right\} \\
N=\left\{v \in \Delta: \exists j \text { with } v \cdot \Omega_{j}+s_{j}(v)=0\right\}
\end{gathered}
$$

Next we use these to define the goods market cone:

Definition 3. The goods market cone $\partial D_{i}$ of agent $i$ is defined as

$$
\partial D_{i}=D_{i} \cap S(\mathcal{F}) \text { if } S(\mathcal{F}) \subset N \text { and } \partial D_{i}=D_{i} \text { otherwise }
$$

In words, if at all supports to allocations that are feasible, efficient, individually rational and affordable, some agent $j$ has zero income (including income from securities transactions) then $\partial D_{i}$ consists of those supporting prices at which only limited increases in utility can be afforded from initial endowments. Otherwise it is the dual of the set of directions in which utility never ceases to increase.

Definition 4. The economy satisfies limited arbitrage in the goods market if there is a price vector at which no agent can always derive increased utility from large zero-cost trades in goods: formally there exists a price vector $p \in \mathfrak{R}_{+}^{n}$ assigning strictly positive value to all vectors in $G_{i}$, for $i=1,2, \ldots, I$ or $\underset{1 \leq i \leq I}{\cap} \partial D_{i} \neq \emptyset$

Limited arbitrage states, roughly, that if all supporting prices to allocations that are efficient, individually rational and affordable imply zero income for some individual, then there is one supporting price at which only limited increases in 
utility are affordable from initial endowments. Otherwise there exists a price at which only limited increases in utility are affordable.

These definitions have to be modified slightly to apply to the securities markets: the commodity space is infinite-dimensional and consumption sets are unbounded. So we have

Definition 5. The securities global cone $\tilde{A}_{i}$ of agent $i$ consists of all directions in the space of securities in which $i$ 's expected utility $W_{i}$ increases without bound:

$$
\tilde{A}_{i}=\left\{z \in L_{2}: \forall y \in L_{2}, \exists \lambda>0: W_{i}\left(s_{i}+\lambda z\right)>W_{i}(y)\right\}
$$

Definition 6. The cone $\tilde{G}_{i}$ is the set of directions in the securities space in which $i$ 's expected utility $W_{i}$ never ceases to increase:

$$
\left.G_{i} \tilde{(} s_{i}\right)=\left\{z \in L_{2}: \forall \mu \exists \lambda: W_{i}\left(s_{i}+\lambda z\right)>W_{i}\left(s_{i}+\mu z\right) \text { if } \lambda>\mu \geq 0\right\}
$$

Definition 7. The securities market cone $\tilde{D}_{i}$ is the set of securities prices assigning positive value to all trades in directions in which expected utility $W_{i}$ never ceases to increase:

$$
\tilde{D}_{i}=\left\{\pi \in L_{2}: \forall z \in \tilde{G}_{i},\langle\pi, z\rangle>0\right\}
$$

where $\langle\pi, z\rangle$ is the inner product of $\pi$ and $z$.

Definition 8 . The economy satisfies limited arbitrage in securities markets if there is a securities price vector at which no agent can always derive increased expected utility from arbitrarily large zero-costs securities trades: formally there exists a price $\pi \in L_{2}$ assigning strictly positive value to all vectors in $\tilde{G}_{i}$ for $i=1,2, \ldots, I$ or $\underset{1 \leq i \leq I}{\cap} \tilde{D}_{i} \neq \emptyset$

Note that while limited goods arbitrage places restrictions on differences between agents' preferences for goods, limited securities arbitrage places limits on differences between agents' preferences for goods and on differences between their price expectations. Even if limited goods arbitrage holds, limited securities arbitrage may fail if expectations are very different. Limited arbitrage is similar in concept to the condition of overlapping or similar expectations used as a sufficient condition for existence of equilibrium in temporary equilibrium models and securities markets models (see Hammond [1983] and Hart [1974]). The underlying intuition is that to ensure the existence of an equilibrium we need a condition on preferences that will prevent any two agents from wanting to take unbounded and opposite positions (Werner [1987]). We do this by defining a cone of rays along which an agent's utility or expected utility increases and then requiring that all such cones intersect.

\section{Equilibrium with Price Insurance}

An equilibrium with price insurance in the economy $\mathcal{E}$ is

(1) A set of PCS prices at which PCS markets clear and such that the associated PCS holdings for each agent maximize her expected utility according to her price expectations in goods markets, as indicated in (3.6), and

(2) A set of goods prices and consumption levels such that markets clear and agents maximize utility as in (3.1). Formally:

Definition 9. An equilibrium with price insurance in the economy $\mathcal{E}$ is a set of PCS prices $\pi^{*} \in L_{2}$, of goods prices $p^{*} \in \Delta$, of PCS holdings $s_{i}^{*}(p) \in L_{2} \forall i$, and of consumption vectors $c_{i}^{*} \in \mathfrak{R}_{+}^{\mathfrak{n}} \forall i$ such that (1) $c_{i}^{*}$ maximizes $u_{i}\left(c_{i}\right)$ subject to $p^{*} \cdot c_{i}^{*} \leq p_{i}^{*} \cdot \Omega_{i}+s_{i}^{*}\left(p^{*}\right)$, and (2) $\sum_{i} c_{i}^{*}=\sum_{i} \Omega_{i}$, and (3) $s_{i}^{*}(p)$ maximizes 
$\int_{\Delta} w_{i}\left(p, s_{i}(p)\right) d e_{i}(p)$ subject to $\int_{\Delta} s_{i}^{*}(p) \pi^{*}(p) d p=0$ and $p^{*} . \Omega_{i}+s_{i}^{*}\left(p^{*}\right) \geq 0$, and (4) $\sum_{i} s_{i}^{*}(p)=0 \forall p$.

\section{REsults}

Theorem 1. Under assumptions 1 to 4, there exists an equilibrium with price insurance in the sense of Definition 9 if and only if the economy satisfies limited arbitrage in the goods market and in the securities market.

The proof is given in the Appendix.

Theorem 2. Any equilibrium with price insurance is Pareto efficient.

Proof. A standard application of the first theorem of welfare economics.

In general, equilibria with price insurance are neither unique nor fully insured. In Chichilnisky et al. [1994] the equilibria are unique and fully insured, but in that paper the assumptions are stronger than here: common price expectations restricted to the set of Walrasian equilibria and the trading of many levels of derivatives. We can however prove the following:

Theorem 3. If all agents have identical price expectations and if the support of these is the set of Walrasian equilibrium price vectors in the underlying exchange economy, then consumption at the equilibrium with price insurance is constant across all possible exchange economy prices.

Proof. By assumption 1 agents are risk averse. Let $\mathfrak{C}_{i}$ be the set of consumption vectors for agent $i$ associated with possible equilibrium price vectors for the exchange economy, with $\mathfrak{c}_{i j}$ an element of this set. Take the probability (common to all agents) of the $j$-th outcome $\mathfrak{c}_{i j}$ to be $\mathfrak{P}_{j}$. Then by risk aversion agent $i$ is better off with an allocation $\sum \mathfrak{c}_{i j} \mathfrak{P}_{j}$ equal to her expected allocation than she is receiving $\mathfrak{c}_{i j}$ with probability $\mathfrak{P}_{j}$. Such an expected allocation is feasible as the total endowment of the exchange economy is independent of the prices realized. This is true for all agents. So at a Pareto efficient allocation agents' consumption vectors must be state independent.

Note that the state-independent consumption vectors that theorem 3 predicts will not be equilibrium consumption vectors of the underlying exchange economy, because endowments will have been altered by trading PCSs.

Theorem 4. In an economy $\mathcal{E}$ with price-contingent securities the equilibrium will differ from any competitive equilibrium in the underlying exchange economy $\mathrm{E}$ if there are non-zero holdings of securities at the equilibrium goods prices.

Proof. Note that the examples of section 2 illustrate this point. Let $\left\{c_{i, k}^{*}, p_{k}^{*}\right\}$ be one of $K$ competitive equilibrium of the exchange economy E. Suppose the economy with PCSs has an equilibrium $\left\{\hat{c}_{i}, \hat{p}, \hat{\pi}(p), \hat{s}_{i}(p)\right\}$ with $\hat{s}_{i}(\hat{p}) \neq 0$ for some $i$. Consider first the case in which $\hat{p}=p_{k}^{*}$ for some $k$. Then agents' budgets are $p^{*} . \hat{c}_{i} \leq p^{*} . \Omega_{i}+\hat{s}_{i}\left(p^{*}\right)$ which differ from their budgets in the exchange economy E. If $\hat{p} \neq p_{k}^{*}$ for any $k$ then the proposition is clearly true.

Note that securities holdings are a function of price expectations $e_{i}(p)$ (this follows from the specification of problem (3.6)) so that the equilibrium allocation in $\mathcal{E}$ is affected by agents' price expectations. 


\section{Conclusions}

A relatively simple extension of the classical general equilibrium framework allows it to incorporate uncertainty about the values of equilibrium prices, a form of uncertainty which is faced by most participants in modern economies yet which is not captured in the current formulations of general equilibrium models. This extension is achieved by the introduction of price-contingent securities, traded in a framework that prevents arbitrage between the markets for these and the goods markets. Conditions for the existence of an equilibrium in such an economy are obvious extensions of those in the classical model.

An interesting open question concerns the determination of the prices of the price-contingent securities: how are these prices related to those of the underlying goods and the expectations that agents hold over these? An answer to this question would provide a general equilibrium approach to the pricing of derivative securities. We know that the prices of these securities must be in the intersection of the cones $\tilde{D}_{i}$ so this already gives some bounds on possible equilibrium prices, bounds related to agents' preferences and expectations.

\section{APPENDIX}

This appendix contains the proofs of the main theorems presented above.

Lemma 1. Let $s_{i}^{*}(p): \Delta \subset \mathfrak{R}_{+}^{\mathfrak{n}} \rightarrow \mathfrak{R}$ be the solution to the consumer's portfolio problem (3.6). Then this is a continuous function.

Proof. This follows immediately from the fact that $s_{i}(p)$ is the solution to an isoperimetric variational problem and so solves a differential equation.

Lemma 2. For a given set of PCS holdings, the exchange economy has a competitive equilibrium if and only if it satisfies limited goods arbitrage (definition 4).

Proof. We can use the proof in Chichilnisky [1995] with one minor modification. On page 97 in the proof of Lemma 3 the correspondence $\varphi$ from the simplex $\Delta$ to the set $T=\left\{y \in \mathfrak{R}^{I}: \sum_{i} y_{i}=0\right\}$ must be modified so that for each $r \in \Delta$

$$
\varphi(r)=\left\{p .\left[\Omega_{1}+s_{1}(p)-x_{1}(r)\right], \ldots ., p .\left[\Omega_{I}+s_{I}(p)-x_{I}(r)\right]: p \in P(r)\right\}
$$

Given that $s_{i}(p)$ is continuous (Lemma 9 above), upper-semi-continuity of $\varphi$ can be established exactly as in Chichilnisky page 97 , and the proof of existence of an equilibrium in that paper can be used to establish the lemma.

\subsection{Proof of Theorem 1.}

Proof. This is direct application of Theorem 5 page 122 of Chichilnisky and Heal [1998]. Consider the exchange economy $\mathcal{H}$ with commodity space and consumption sets $L_{2}$, preferences $W_{i}\left(s_{i}(p)\right): L_{2} \rightarrow \mathfrak{R}$ and initial endowments $0 \in L_{2}$. This is an exchange economy that satisfies all the conditions of Theorem 5 of Chichilnisky and Heal [1998] and for which the existence of a competitive equilibrium is (by Theorem 5 of Chichilnisky and Heal [1998]) equivalent to the limited arbitrage condition of that paper, which in the present contexts is exactly what we have called limited securities arbitrage. Hence under the conditions of the main theorem the economy $\mathcal{H}$ has a competitive equilibrium. This means that there exists a set of securities prices $\pi^{*}(p)$ and a set of PCS holdings for each agent $s_{i}^{*}(p)$ such that markets for PCSs clear, $\sum_{i} s_{i}^{*}(p)=0 \forall p \in \Delta$, and all agents are optimizing subject 
to their budget constraints, i.e. for all $i, s_{i}^{*}(p)$ maximizes $\int_{\Delta} w_{i}\left(p, s_{i}^{*}(p)\right) e_{i}(p) d p$ subject to $\int_{\Delta} s_{i}^{*}(p) \pi^{*}(p) d p=0$ and $p \cdot \Omega_{i}+s_{i}(p) \geq 0$. By Lemma 2 given any set of PCS holdings, and so in particular the equilibrium holdings $s_{i}^{*}(p)$, the goods economy has a competitive equilibrium. Let the prices at this equilibrium be $p^{*}$ and the consumption vectors $c_{i}^{*} \forall i$. Then the securities holdings $s_{i}^{*}(p$,$) securities$ prices $\pi^{*}(p)$, goods prices $p^{*}$ and consumption vectors $c_{i}^{*}$ satisfy all the conditions of the definition of an equilibrium with price-contingent securities. This completes the proof of the main theorem.

\section{REFERENCES}

Graciela Chichilnisky. Limited arbitrage is necessary and sufficient for the existence of a competititive equilibrium with and without short sales. Economic Theory, 5(1):79-107, 1995.

Graciela Chichilnisky and Geoffrey Heal. A unified treatment of finite and infinite economies: limited arbitrage is necessary and sufficient for the existence of equilibrium and the core. Economic Theory, 12:163-176, 1998.

Graciela Chichilnisky, Jayasri Dutta, and Geoffrey Heal. Price uncertainty and derivative securities. Working paper, Columbia Business School, 1994.

Jerome de Temple and Larry Selden. A general equilibrium analysis of option and stock market interactions. International Economic Review, 1991.

Jacques Dreze. Markets Information and Uncertainty: Essays in Honor of Kenneth J.Arrow, chapter Chapter 3: The Formulation of Uncertainty: Prices and States, pages 44-66. Cambridge University Press, 1999.

Frank Hahn. Markets Information and Uncertainty: Essays in Honor of Kenneth J.Arrow, chapter Chapter 4: A Remark on Incomplete Market Equilibrium, pages 67-71. Cambridge University Press, 1999.

Peter Hammond. Overlapping expectations and hart's condition for the existence of equilibrium in a securities market. Journal of Economic Theory, 31:170-175, 1983.

Oliver Hart. Existence of equilibrium in a securities market. Journal of Economic Theory, 9:291-311, 1974.

Phillipe Henrotte. Existence and optimality of equilibria in markets with tradable derivative securities. Technical Report 48, Stanford Institute for Theoretical Economics, 1992.

Mordecai Kurz and Ho-Mou Wu. Endogenous uncertainty in a general equilibrium model with price-contingent contracts. Economic Theory, 8:461-488, 1996.

Robert Shiller. Macro Markets: Creating Markets for Managing Society's Largest Risks. Oxford University Press, 1993.

Bengt Stigum. Balanced growth under uncertainty. Journal of Economic Theory, $5: 42-68,1972$.

Lars E.O. Svensson. Efficiency and speculation in a model with price contingent contracts. Econometrica, 49(1):131-151, 1981.

Jan Werner. Arbitrage and the existence of competitive equilibrium. Econometrica, 55(6):1403-1418, 1987.

Columbia Business School 